\title{
BMJ Methods used to conduct and report OPOn Bayesian mixed treatment comparisons published in the medical literature: a systematic review
}

\author{
Diana M Sobieraj, ${ }^{1}$ Joseph C Cappelleri, ${ }^{2}$ William L Baker, ${ }^{1}$ Olivia J Phung, ${ }^{1}$ \\ C Michael White, ${ }^{1}$ Craig I Coleman ${ }^{1}$
}

To cite: Sobieraj DM, Cappelleri JC, Baker WL, et al. Methods used to conduct and report Bayesian mixed treatment comparisons published in the medical literature:

a systematic review. BMJ Open 2013;3:e003111. doi:10.1136/bmjopen-2013003111

- Prepublication history and additional material for this paper is available online. To view these files please visit the journal online (http://dx.doi.org/10.1136/ bmjopen-2013-003111).

Received 24 April 2013 Revised 12 June 2013 Accepted 17 June 2013

\footnotetext{
${ }^{1}$ University of Connecticut/ Hartford Hospital Evidencebased Practice Center, Hartford, Connecticut, USA 2Department of Biostatistics, Pfizer, Groton, Connecticut, USA
}

Correspondence to Dr Craig I Coleman; ccolema@harthosp.org

\section{ABSTRACT \\ Objectives: To identify published closed-loop} Bayesian mixed treatment comparisons (MTCs) and to summarise characteristics regarding their conduct and reporting.

Design: Systematic review.

Methods: We searched multiple bibliographic databases (January 2006-31 July 2011) for full-text, English language publications of Bayesian MTCs comparing the effectiveness or safety of $\geq 3$ interventions based on randomised controlled trials and having at least one closed loop. Methodological and reporting characteristics of MTCs were extracted in duplicate and summarised descriptively.

Results: We identified 34 Bayesian MTCs spanning 13 clinical areas. Publication of MTCs increased over the 5-year period; with $76.5 \%$ published during or after 2009. MTCs included a mean $( \pm S D)$ of $35.9 \pm 30.1$ trials ( $n=33459 \pm 71233$ participants) and $8.5 \pm 4.3$ interventions (85.7\% pharmacological). Noninformative and informative prior distributions were reported to be used in $44.1 \%$ and $8.8 \%$ of MTCs, respectively, with the remainder failing to specify the prior used. A random-effects model was used to analyse the networks of trials in $58.5 \%$ of MTCs, all using WinBUGS; however, code was infrequently provided (20.6\%). More than two-thirds of MTCs $(76.5 \%)$ also conducted traditional meta-analysis. Methods used to evaluate convergence,

heterogeneity and inconsistency were infrequently reported, but from those providing detail, methods appeared varied. MTCs most often used a binary effect measure $(85.3 \%)$ and ranking of interventions based on probability was common $(61.8 \%)$, although rarely displayed in a figure (8.8\% of MTCs). MTCs were published in 24 different journals with a mean impact factor of $9.20 \pm 8.71$. While $70.8 \%$ of journals imposed limits on word counts and $45.8 \%$ limits on the number of tables/figures, online supplements/appendices were allowed in $79.2 \%$ of journals. Publication of closed-loop Bayesian MTCs is increasing in frequency, but details regarding their methodology are often poorly described. Efforts in clarifying the appropriate methods and reporting of Bayesian MTCs should be of priority.

\section{ARTICLE SUMMARY}

Article focus

- To identify published closed-loop Bayesian mixed treatment comparisons (MTCs) and to summarise characteristics regarding their conduct and reporting.

Key messages

- We identified 34 closed-loop Bayesian MTCs spanning 13 clinical areas, published in 24 different journals.

- Closed-loop Bayesian MTCs are increasing in frequency, but details regarding their methodology are often poorly described. Efforts in clarifying the appropriate methods and reporting of Bayesian MTCs should be of priority.

Strengths and limitations of this study

- Our systematic review adds to this existing literature by updating results and adding new information as prior reviews only included literature through 2007/2008. Unlike prior publications, our systematic review focused only on Bayesian MTCs of networks with at least one closed loop.

- Unlike prior reviews, we evaluated reporting of additional model characteristics in depth including testing for model fit, evaluation of convergence, adjustment for covariates or multiarm trials, the specific priors used and availability of the code and aggregated study-level data.

- An important limitation of our review is that we cannot say with certainty that a lack of reporting means a given method or analysis was not undertaken (ie, the testing for convergence or inconsistency need not be described in a paper for it to have been performed by the investigators) or that the reporting of a piece of data or statistical code was not considered.

\section{INTRODUCTION}

Clinicians and decision-makers often need to select from multiple available interventions when determining the optimal treatment for a disease. Ideally, high-quality randomised 
controlled trials (RCTs) that estimate the effectiveness of all possible interventions directly against one another would be available to guide decision-making. ${ }^{1-4}$ However, interventions are commonly compared with placebo or non-active control in RCTs rather than another active intervention. When direct comparative trials are completed, they typically include only two interventions from a larger group of possible treatments. As such, decision-makers are faced with a lack of adequate direct comparative data with which to make their judgements.

In the absence of head-to-head trials, indirect comparisons may provide valuable information. For example, if two different interventions have been evaluated against a common comparator, the comparative effects of the two interventions versus each other can be estimated indirectly. ${ }^{12}$ Even in the presence of head-to-head data, indirect comparisons may add value by improving precision of treatment effect estimates.

Methodologies exist to indirectly compare interventions, as do modes to implement such methodologies. ${ }^{15-8}$ In the simplest form, interventions that are evaluated against a common comparator in separate trials can be compared using an anchored-indirect treatment comparison approach. ${ }^{5}$ As a generalisation of indirect comparisons, when more than two treatments are being compared indirectly, and at least one pair of treatments is being compared directly as well as indirectly (a closed loop is present), both direct and indirect types of data can be used to estimate effects in a mixed treatment comparison (MTC) meta-analysis using a Bayesian or frequentist framework. ${ }^{1-8}$ Prior research has attempted to categorise the use of indirect comparisons in the medical literature, but either did not included Bayesian MTCs or collected limited data on this approach. ${ }^{9}{ }^{10}$ The Agency for Healthcare Research and Quality commissioned us to evaluate how MTCs in published systematic reviews are conducted and reported. ${ }^{11}$ We present the findings of our systematic review identifying closed-loop MTCs using a Bayesian framework and descriptively summarise their methodological and reporting characteristics.

\section{METHODS}

A systematic literature search was conducted in MEDLINE, the Centre for Reviews and Dissemination Databases (including the Database of Abstracts and Reviews of Effects, Health Technology Assessment and the National Institute for Health Research Economic Evaluation Database), The Cochrane Library and the American College of Physicians Journal Club from 1 January 2006 through 31 July 2011. The search strategy in online supplementary appendix S1 was used. Manual additions were permitted based on the citations identified by the literature search.

Two independent investigators assessed citations for inclusion in a parallel manner based on a priori defined criteria. Specifically, we included meta-analyses that compared the clinical effectiveness or safety of interventions (any pharmacological (including placebo and different doses), behavioural or procedural interventions) based on RCTs, utilised a Bayesian approach to conduct MTC, had at least one closed loop (see online supplementary appendix S2) and were published in full-text and in the English language. There has been inconsistency in what constitutes a MTC in the medical literature ${ }^{12}$; therefore, for the purposes of this systematic review a MTC was defined as the comparison of three or more interventions in which direct as well as indirect evidence was used. Methodological publications that presented MTCs for illustrative purposes and cost-effectiveness analyses were not considered in this systematic review, nor were individual patient data meta-analyses.

Two reviewers independently extracted data with disagreements resolved through discussion. For each included closed-loop Bayesian MTC, all published material including the manuscript, supplements, appendices or external websites which the reader of the article was referred to for additional information were used during data extraction. Therefore, the extraction of data was predicated on the reporting of the information by the authors within these sources. When extracting data, we recorded what the authors reported without ourselves judging whether the methods were appropriate or not. If there was insufficient data from all available sources, we indicated 'not reported' for that criterion on data extraction.

General characteristics of each MTC were extracted including author and funding information, if a methodologist was an author, the number and type of intervention comparisons made, number of printed pages and use of supplement or appendix, the number of trials and patients in the analyses, clinical area (eg, cardiology and endocrinology) and the network pattern. For the purpose of this project, we defined a methodologist as an individual having an affiliation with a department of statistics, biostatistics, epidemiology, clinical epidemiology or public health services, as determined by author information and affiliations listed in the publication. ${ }^{13}$ The country in which a review was conducted was determined by the corresponding author's affiliation.

The network pattern ${ }^{3} 4^{4} 111^{14}$ was determined by figures presented within the identified publication. If a figure was not available, we determined the pattern based on text descriptions of included trials.

We also extracted information regarding the methodology used to conduct the closed-loop Bayesian MTC including the models applied (eg, fixed vs random effects), description of model parameters (eg, choices of prior distributions), methods for assessment of model fit, potential bias, inconsistency and heterogeneity, use of covariate adjustment in models, whether the model accommodated multiarm trials, software utilised and availability of code.

Finally, we extracted data concerning the reporting of results including the type of endpoint (eg, binary vs continuous), effect size and measure of variance, use of 
other methods to report results (eg, probability of treatment being best, claims of equivalence or noninferiority) and the format/presentation of results (eg, text, tables and figures). Characteristics of the journals in which included MTCs were published were collected, including journal name, impact factor, allowance of supplements or appendices, and limitations on word, table and figure counts.

The characteristics of the closed-loop Bayesian MTCs and journals were summarised descriptively. Categorical data are presented using frequencies and continuous data as means \pm SDs.

\section{RESULTS}

A total of 626 citations were identified through the database searches with an additional five MTCs identified through manual review (figure 1). After full text review, 35 articles representing 34 unique closed-loop Bayesian MTCs were included. ${ }^{15-49}$ The publication by Orme et $a l^{25}$ analysed two distinct networks of RCTs.

The rate of publication of closed-loop Bayesian MTCs increased over the 5-year search period, with $26(76.5 \%)$ of the MTCs published between 2009 and 2011 compared with only $8(23.5 \%)$ published prior to 2009 . On average, $6.1 \pm 4.8$ authors were listed per publication and less than half of publications $(47.1 \%)$ included a methodologist as an author (table 1). The most common country from which authors published MTCs was the UK (35.3\%), followed by the USA (11.8\%) and Greece $(11.8 \%)$.

Funding sources for the MTCs included governmental/foundation (29.4\%), industry $(26.5 \%)$ and unfunded $(17.6 \%)$ with $23.6 \%$ not making a statement regarding funding source(s). Only two publications

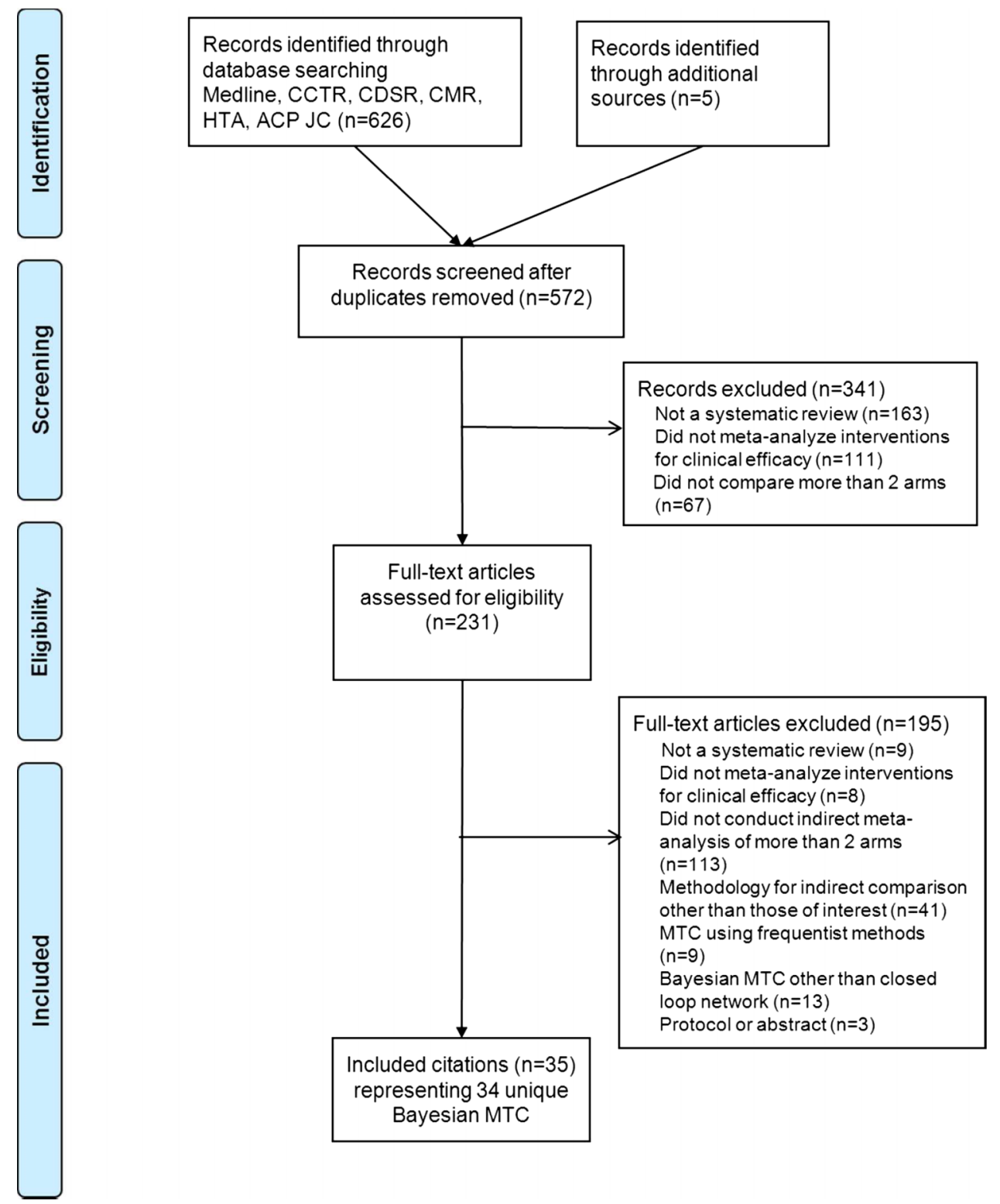

Figure 1 Flow diagram of citation inclusion and exclusion. 
Table 1 General characteristics of Bayesian mixed treatment comparisons

\begin{tabular}{|c|c|}
\hline Characteristic & $\begin{array}{l}n / N(\%) \text { or } \\
\text { mean (SD) }\end{array}$ \\
\hline Number of authors & $6.1(4.8)$ \\
\hline $\begin{array}{l}\text { Was a methodologist an author on the } \\
\text { manuscript? }\end{array}$ & $16 / 34(47.1)$ \\
\hline \multicolumn{2}{|l|}{ Country } \\
\hline USA & 4/34 (11.8) \\
\hline UK & 12/34 (35.3) \\
\hline Canada & 2/34 (5.9) \\
\hline Brazil & $1 / 34(2.9)$ \\
\hline China & $2 / 34(5.9)$ \\
\hline Switzerland & $3 / 34(8.8)$ \\
\hline The Netherlands & $1 / 34(2.9)$ \\
\hline Italy & $3 / 34(8.8)$ \\
\hline Belgium & $1 / 34(2.9)$ \\
\hline Greece & $4 / 34(11.8)$ \\
\hline \multicolumn{2}{|l|}{ Funding } \\
\hline Industry & 9/34 (26.5) \\
\hline Government/foundation & $10 / 34(29.4)$ \\
\hline Unfunded & 6/34 (17.6) \\
\hline Other & $1 / 34(2.9)$ \\
\hline Not reported & $8 / 34(23.6)$ \\
\hline Declared affiliation & $2 / 34(5.9)$ \\
\hline Health Technology Assessment & $1 / 2(50.0)$ \\
\hline \multicolumn{2}{|l|}{ Program } \\
\hline The Cochrane Collaboration & $1 / 2(50.0)$ \\
\hline Number of printed pages & $16.6(36.3)$ \\
\hline Supplement or appendix published & 20/34 (58.8) \\
\hline \multicolumn{2}{|l|}{ Disease state evaluated } \\
\hline Behavioural health & 4/34 (11.8) \\
\hline Cardiology & 6/34 (17.6) \\
\hline Infectious disease & 2/34 (5.9) \\
\hline Endocrine & 2/34 (5.9) \\
\hline Pulmonary & 2/34 (5.9) \\
\hline Pain & $3 / 34(8.8)$ \\
\hline Dermatology & 2/34 (5.9) \\
\hline Ophthalmology & 2/34 (5.9) \\
\hline Rheumatology & 2/34 (5.9) \\
\hline Gastroenterology & $3 / 34(8.8)$ \\
\hline Dental & $1 / 34(2.9)$ \\
\hline Oncology & $4 / 34(11.8)$ \\
\hline Substance abuse & $1 / 34(2.9)$ \\
\hline Number of interventions compared* & $8.5(4.3)$ \\
\hline \multicolumn{2}{|l|}{ Type of intervention* } \\
\hline Pharmacological & $30 / 35(85.7)$ \\
\hline Devices & $3 / 35(8.6)$ \\
\hline Other & $1 / 35(2.9)$ \\
\hline Device and pharmacological & $1 / 35(2.9)$ \\
\hline Number of trials included in network ${ }^{\star}$ & $35.9(30.1)$ \\
\hline Number of patients included in network ${ }^{*}$ & 33459 (71 233) \\
\hline
\end{tabular}

identified an organisational affiliation, one each with the Health Technology Assessment Program and The Cochrane Collaboration. The mean number of printed pages per publication was $16.6 \pm 36.3$ (range 4-221) and over half published a supplement or appendix. From those that did not publish a supplement or appendix, one publication did not have the option to do so, given journal (or report) specifications.

There were 13 different categories of disease states evaluated among included MTCs. The mean number of interventions included within the analyses was $8.5 \pm 4.3$, of which most were pharmacological $(85.7 \%)$ in nature. The mean number of trials included in the MTCs was $35.9 \pm 30.1$ and the mean number of patients included was $33459 \pm 71233$ (range 594-324 168).

The most common model used in closed-loop Bayesian MTCs was a random-effects model $(58.5 \%$; table 2). Very few analyses reported information about whether there was adjustment for covariates $(25.6 \%)$. Of the 28 MTCs that included trials with three or more arms, $10(35.7 \%)$ reported use of an adjustment for multiarm trials. Less than half of all analyses reported testing model fit. Of the 15 analyses that reported testing model fit in some manner, the most common method was residual deviance $(40 \%)$. More than two-thirds of the MTCs $(76.5 \%)$ also included a traditional meta-analysis.

Closed-loop Bayesian MTCs used WinBUGS software, and two also specified the use of additional software including the BUGS XLA Wrapper and S-Plus. The statistical WinBUGS code was made available to the reader in only $20.6 \%$ of cases, most often in an online supplement/appendix (71.4\%). Aggregated study-level patient data used in the MTC was frequently made available to the reader and of these 21 analyses $(61.8 \%)$ it was most commonly published within the manuscript itself $(85.7 \%)$. Evaluation of convergence was found in $35.3 \%$ of analyses, most commonly using the Gelman-Rubin statistic $(58.3 \%)$.

Utilised priors were reported as either non-informative (vague or flat) or informative in $44.1 \%$ and $8.8 \%$ of analyses, respectively. The remaining analyses $(47.1 \%)$ did not specify the nature of the prior distributions used. It was also uncommon for the actual prior distribution to be reported for the population treatment effect (d) and the between-study SD of population treatment differences across studies $(\sigma)$; with only $32.4 \%$ and $29.4 \%$ of MTCs, respectively, reporting this information. Sensitivity analyses based on priors were conducted in $11.8 \%$ of MTCs.

Accompanying traditional meta-analyses were common $(61.5 \%)$. The most common method used to assess heterogeneity was the $\mathrm{I}^{2}$ statistic $(81.3 \%)$ followed by the Cochrane Q-statistic (43.8\%). Evaluation of heterogeneity within the MTC was less common, reported in only $32.4 \%$ of publications. Of these 11 analyses, $\tau^{2}$ (among-study variance of true effects) was used in $54.5 \%$ of analyses followed by between-study SD (45.5\%) and several other less frequent methods (some MTCs reported multiple means to test for heterogeneity and therefore are counted twice in the numerator).

Inconsistency between indirect and direct estimates was evaluated in $24(70.6 \%)$ studies. One review 
reported being unable to evaluate inconsistency due to lack of direct data while the remaining MTCs simply did not comment on inconsistency. The most common

Table 2 Methods characteristics in Bayesian MTCs

\begin{tabular}{|c|c|}
\hline Characteristic & $\mathrm{n} / \mathrm{N}(\%)$ \\
\hline Conducted traditional meta-analysis & $26 / 34(76.5)$ \\
\hline \multicolumn{2}{|l|}{ Model } \\
\hline Fixed effects & 1/34 (2.9) \\
\hline Random effects & $20 / 34(58.8)$ \\
\hline Fixed and random effects & 7/34 (20.6) \\
\hline Not reported & $6 / 34(17.6)$ \\
\hline Adjustment for covariates & 9/34 (25.6) \\
\hline $\begin{array}{l}\text { Adjustment for multiple arms in MTCs } \\
\text { including trials with three or more arms }\end{array}$ & 10/28 (35.7) \\
\hline Model fit tested & $15 / 34(44.1)$ \\
\hline Residual deviance & $6 / 15(40.0)$ \\
\hline Deviance information criterion & 2/15 (13.3) \\
\hline Residual deviance and deviance & $3 / 15(20.0)$ \\
\hline \multicolumn{2}{|l|}{ information criterion } \\
\hline $\mathrm{Q}-\mathrm{Q}$ plots & $1 / 15(6.7)$ \\
\hline Mean sum deviation & $1 / 15(6.7)$ \\
\hline Method not reported & $2 / 15(13.3)$ \\
\hline Code published & $7 / 34(20.6)$ \\
\hline Online supplement & $5 / 7(71.4)$ \\
\hline External website & $2 / 7(28.6)$ \\
\hline Aggregate study-level data published & $21 / 34(61.8)$ \\
\hline Manuscript & $18 / 21(85.7)$ \\
\hline Online supplement & 2/21 (9.5) \\
\hline External website & $1 / 21(4.8)$ \\
\hline Evaluation of convergence* & $12 / 34(35.3)$ \\
\hline Gelman Rubin statistic & $7 / 12(58.3)$ \\
\hline Kernel density plot & $1 / 12(8.3)$ \\
\hline Visual plot inspection & $1 / 12(8.3)$ \\
\hline Observation of chain mix & $2 / 12(16.7)$ \\
\hline Method not reported & $2 / 12(16.7)$ \\
\hline \multicolumn{2}{|l|}{ Priors } \\
\hline Use of non-informative & $15 / 34(44.1)$ \\
\hline Use of informative priors & $3 / 34(8.8)$ \\
\hline Not specified & $16 / 34(47.1)$ \\
\hline Prior distribution of $d$ reported & 11/34 (32.4) \\
\hline Prior distribution for $\sigma$ reported & 10/34 (29.4) \\
\hline Sensitivity analysis based on priors & 4/34 (11.8) \\
\hline $\begin{array}{l}\text { Evaluation of heterogeneity in traditional } \\
\text { meta-analysis }{ }^{\star}\end{array}$ & $16 / 26(61.5)$ \\
\hline $1^{2}$ & $13 / 16(81.3)$ \\
\hline Cochrane- $Q$ statistic & 7/16 (43.8) \\
\hline PICO statement & $1 / 16(6.3)$ \\
\hline Plot visualisation & $2 / 16(12.5)$ \\
\hline L'Abbe plot & $1 / 16(6.3)$ \\
\hline $\begin{array}{l}\text { Evaluation of heterogeneity in network } \\
\text { meta-analysis* }\end{array}$ & $11 / 34(32.4)$ \\
\hline Precision $\left(\tau^{2}\right)$ & $6 / 11(54.5)$ \\
\hline Between study SD & $5 / 11(45.5)$ \\
\hline Heterogeneity $p$ values & $1 / 11(9.1)$ \\
\hline Evaluation of inconsistency* & $24 / 34(70.6)$ \\
\hline $\begin{array}{l}\text { Comparison to traditional or prior } \\
\text { meta-analysis } \dagger\end{array}$ & $12 / 24(50.0)$ \\
\hline
\end{tabular}

Continued

\begin{tabular}{lc} 
Table 2 Continued & \\
\hline Characteristic & $\mathbf{n} / \mathbf{N}(\%)$ \\
\hline Inconsistency/incoherence factors & $4 / 12(33.3)$ \\
Posterior mean residual deviance & $3 / 12(25.0)$ \\
Method not reported & $4 / 12(33.3)$ \\
Trial sequential analysis & $1 / 12(8.3)$ \\
Overall inconsistency $\left(\sigma^{2}\right.$ w) & $1 / 12(8.3)$ \\
\hline *Studies that used multiple methods to test heterogeneity were \\
counted multiple times, in the respective categories. \\
†Authors either compared results of the MTC with a traditional \\
meta-analysis that they conducted concurrently or with a \\
traditional meta-analysis that was previously published. \\
MTC, mixed treatment comparison; PICO, patient, intervention, \\
comparator, outcome.
\end{tabular}

method used to evaluate inconsistency was comparing results of the MTC to those of a traditional meta-analysis conducted by the authors simultaneously or a previously published traditional meta-analysis.

Most analyses $(85.3 \%)$ reported outcomes that were binary (table 3). Of these 29 analyses, ORs were the most commonly reported effect measure $(62.1 \%)$, followed by relative risks $(17.2 \%)$ and HRs (13.8\%), among other less frequent measures. Of the $10(29.4 \%)$ analyses that reported continuous outcomes, the weightedmean difference was the most common effect measure $(80 \%)$. All analyses reported variance with $95 \%$ credible intervals and one also reported SEs. Most analyses did not report if the posterior distribution was the mean or median value $(85.3 \%)$. Presentation of results varied, although most analyses used multiple media including tables, figures and text.

Few analyses $(8.8 \%)$ presented graphical representations of the posterior distributions of outcomes. Rank-ordering of interventions based on probability statements (including rankograms with the probability of a treatment being best, second best and so on) for a given outcome was reported in $21(61.8 \%)$ of the MTCs. Only one MTC made claims of equivalence and two made claims of noninferiority, of which two defined the minimally important difference required to make these statements.

Complete details of each journal in which at least one MTC was published can be found in tables 4 and 5. The 34 MTCs were published in 24 different journals, with a mean impact factor of $9.20 \pm 8.71$. BMJ published the most MTCs (6 of the 34, 17.6\%) followed by Current Medical Research and Opinion (4 of the 34,11.8\%). The majority of journals $(70.8 \%)$ imposed word count limits and $45.8 \%$ imposed table/figure limitations; however, $79.2 \%$ of journals allowed online supplements or appendices.

\section{DISCUSSION}

Meta-analysis has been regarded as the most highly cited study design in health science. ${ }^{50}$ However, a drawback of the traditional meta-analysis is its ability to compare only two interventions, without the ability to simultaneously evaluate other comparators. This is inconsistent with 
Table 3 Outcomes and results reporting in Bayesian mixed treatment comparisons

\begin{tabular}{|c|c|}
\hline Characteristic & $\begin{array}{l}\mathrm{n} / \mathrm{N}(\%) \text { or } \\
\text { mean (SD) }\end{array}$ \\
\hline $\begin{array}{l}\text { Graphical representation of } \\
\text { posterior distribution }\end{array}$ & $3 / 34(8.8)$ \\
\hline Ranking of outcomes & $21 / 34(61.8)$ \\
\hline Claims of equivalence & $1 / 34(2.9)$ \\
\hline Claims of non-inferiority & $2 / 34(5.9)$ \\
\hline Minimally important difference & $8 / 47(17.0)$ \\
\hline \multicolumn{2}{|l|}{ Type of outcome } \\
\hline Binary & $23 / 34(67.6)$ \\
\hline Continuous & 4/34 (11.8) \\
\hline Binary and continuous & $6 / 34(17.6)$ \\
\hline Categorical non-binary & $1 / 34(2.9)$ \\
\hline Binary effect measure & 29/34 (85.3) \\
\hline Relative risk & $5 / 29(17.2)$ \\
\hline OR & $18 / 29(62.1)$ \\
\hline $\mathrm{HR}$ & 4/29 (13.8) \\
\hline Multiple effect measures & 2/39 (6.9) \\
\hline Continuous effect measure & $10 / 34(29.4)$ \\
\hline Weighted mean difference & $8 / 10(80.0)$ \\
\hline Multiple & $2 / 10(20.0)$ \\
\hline Categorical non-binary effect measure & $1 / 34(2.9)$ \\
\hline Relative risk & $1 / 1(100)$ \\
\hline \multicolumn{2}{|l|}{ Presentation of results* } \\
\hline Table & $24 / 34(70.6)$ \\
\hline Text & $32 / 34(94.1)$ \\
\hline Figure & $21 / 34(61.8$ \\
\hline \multicolumn{2}{|l|}{ Posterior distribution } \\
\hline Mean & 1/34 (2.9) \\
\hline Median & 4/34 (11.8) \\
\hline Not reported & 29/34 (85.3) \\
\hline
\end{tabular}

clinical practice as in many instances there are a variety of interventions that exist and one must decide which is best. The use of statistical methods (including simple approaches as well as MTC meta-analysis) to compare greater than two interventions simultaneously is on the rise within the peer-reviewed literature. As recent as 2005, a search of the medical literature yielded four publications that utilised such methods; while in 2011, the number increased to $57 .{ }^{12}$ The results of our systematic

\begin{tabular}{lc}
\multicolumn{2}{l}{ Table 4 Aggregate journal characteristics } \\
\hline Characteristics & \multicolumn{1}{c}{ Yes $\mathrm{n} / \mathrm{N}(\%)$ or } \\
mean (SD)
\end{tabular}

review also suggest that indirect comparisons, specifically closed-loop Bayesian MTC, have become more prevalent. A recent study found that a median of three studies (IQR 2-6) were included per meta-analysis, with close to $75 \%$ of meta-analyses including five or less trials. ${ }^{51}$ Our results suggest that compared to traditional meta-analyses, closed-loop Bayesian MTCs are larger and more comprehensive. Moreover, identified MTCs were published in a wide variety of journals covering a range of disease states and thus likely to reach a large readership given their collective mean impact factor. However, we found a variety of reporting strategies or a lack of reporting of characteristics that are important to the conduct of closed-loop Bayesian MTC. This may be related to the limited guidance as to how to conduct and report an MTC, a topic which has been extensively reviewed and summarised elsewhere. ${ }^{11}$

Prior research by Donegan et at has attempted to categorise published indirect comparisons and evaluate their quality, although advanced methods including Bayesian (and frequentist) MTCs were not included. Of the 43 included comparisons, 23 used an anchored indirect approach while others used hypothesis testing, CI overlap and meta-regression methods to draw indirect comparisons. The authors concluded that quality of published indirect comparisons, in particular the assessment of model assumptions and the methods used to do so, were suboptimal. A set of quality criteria were proposed by the authors to be used in future indirect comparisons, specifically evaluating if the method of indirect comparison applied was appropriate, if methods to assess similarity, homogeneity and consistency were stated and if such methods were appropriate, and details of overall interpretation and reporting of results.

Song et $a l^{10}$ also have systematically reviewed previously published indirect comparisons and, of the 88 identified, found only 18 using 'network or Bayesian approaches'. Their findings are similar to that of Donegan and colleagues, suggesting that the main methodological problems included unclear understanding of assumptions, incomplete inclusion of relevant studies, flawed or inappropriate methods, lack of similarity assessment and inappropriate combination of direct and indirect evidence.

Our systematic review adds to this existing literature by updating results and adding new information. First, the aforementioned prior reviews only included literature through 2007/2008, making ours the most up-to-date review available. Unlike prior publications, our systematic review focused only on Bayesian MTCs of networks with at least one closed loop, perhaps the most common method utilised of late to analyse complex networks of RCTs. While prior publications focused on the evaluation and reporting of assumptions made within the models, we evaluated additional model characteristics in depth including testing for model fit, evaluation of convergence, adjustment for covariates or multiarm trials, the specific priors used and availability of the code and 


\begin{tabular}{|c|c|c|c|c|c|c|}
\hline Journals & Included studies & $\begin{array}{l}\text { Impact } \\
\text { factor* }^{*}\end{array}$ & $\begin{array}{l}\text { Supplement or } \\
\text { appendix; format }\end{array}$ & $\begin{array}{l}\text { Word count } \\
\text { limit }\end{array}$ & Table limit & Figure limit \\
\hline $\begin{array}{l}\text { Alimentary Pharmacology and } \\
\text { Therapeutics }\end{array}$ & Edwards $^{36}$ & 3.861 & Y, online & $\mathrm{N}$ & $\mathrm{N}$ & $\mathrm{N}$ \\
\hline Annals of Internal Medicine & Gross et $a l^{16}$ & 16.792 & Y, not specified & $3500-4000$ & 4 tables or figures & 4 tables or figures \\
\hline Archives of Internal Medicine & Sciarretta et $a{ }^{20} ;$ Cooper et $a{ }^{47}$ & 10.639 & Y, online & 3500 & $6-8$ tables or figures & $6-8$ tables or figures \\
\hline$B M J$ & $\begin{array}{l}\text { Baldwin et } a f^{49} ; \text { Hartling et } a l^{17} ; \\
\text { Stettler }{ }^{43} \text {; Trelle et } a{ }^{21} ; \text { Wandel et } a l^{30} \text {; } \\
\text { Lam and Owen }{ }^{45}\end{array}$ & 13.471 & Y, online & $\mathrm{N}$ & $\mathrm{N}$ & $\mathrm{N}$ \\
\hline British Journal of Anaesthesia & Maund et $a l^{18} \dagger$ & 4.224 & Y, online & 5000 & $\mathrm{~N}$ & $\mathrm{~N}$ \\
\hline $\begin{array}{l}\text { British Journal of } \\
\text { Ophthalmology }\end{array}$ & Van den Bruel et af3 & 2.934 & Y, online & 3000 & 5 tables or figures & 5 tables or figures \\
\hline Cancer Treatment Reviews & Golfinopoulus et $a /^{38}$ & 6.811 & $\mathrm{~N}$ & $\mathrm{~N}$ & $\mathrm{~N}$ & $\mathrm{~N}$ \\
\hline Clinical Therapeutics & Edwards $^{37}$ & 2.551 & Y, online & $5500-6000$ & $\mathrm{~N}$ & $\mathrm{~N}$ \\
\hline $\begin{array}{l}\text { Cochrane Database of } \\
\text { Systematic Reviews }\end{array}$ & Walsh et $a l^{29}$ & 6.186 & $\mathrm{~N}$ & $\mathrm{~N}$ & $\mathrm{~N}$ & $\mathrm{~N}$ \\
\hline $\begin{array}{l}\text { Current Medical Research } \\
\text { and Opinion }\end{array}$ & $\begin{array}{l}\text { van de Kerkhof et } a^{22} ; \text { Orme et } a^{25} ; \\
\text { Uthman and Abdulmalik } \\
\text { Vissers et } a^{28}\end{array}$ & $2.609^{*}$ & Y, online & 11200 & $\mathrm{~N}$ & $\mathrm{~N}$ \\
\hline Dermatology & Bansback et $a \beta^{34}$ & 2.714 & Y, not specified & $\begin{array}{l}13 \text { pages for } \\
\text { text, tables, } \\
\text { figures }\end{array}$ & $\begin{array}{l}\text { Included in page } \\
\text { count }\end{array}$ & $\begin{array}{l}\text { Included in page } \\
\text { count }\end{array}$ \\
\hline $\begin{array}{l}\text { Drug and Alcohol } \\
\text { Dependence }\end{array}$ & Meader ${ }^{40}$ & 3.365 & Y, online & 6000 & $\mathrm{~N}$ & $\mathrm{~N}$ \\
\hline Gastroenterology & Woo et $a^{\beta 2}$ & 12.023 & Y, online & 6000 & $\begin{array}{l}\text { Minimum of } 4-6 \\
\text { figures or illustrations }\end{array}$ & $\begin{array}{l}\text { Minimum of } 4-6 \\
\text { figures or illustrations }\end{array}$ \\
\hline $\begin{array}{l}\text { Health technology } \\
\text { assessment (Winchester, } \\
\text { England) }\end{array}$ & Maund et al ${ }^{18} \dagger$ & 4.197 & $\mathrm{~N}$ & $\mathrm{~N}$ & $\mathrm{~N}$ & $\mathrm{~N}$ \\
\hline $\begin{array}{l}\text { The Journal of the American } \\
\text { Medical Association }\end{array}$ & Phung et $a^{26}$ & 30 & Y, online & 3500 & 4 tables or figures & 4 tables or figures \\
\hline Journal of Hospital Infection & Wang et $a \beta^{\beta 1}$ & 3.078 & $\mathrm{~N}$ & 5000 & $\mathrm{~N}$ & $\mathrm{~N}$ \\
\hline Journal of Hypertension & Coleman et $\left.a\right|^{41}$ & 3.98 & Y, online & $\mathrm{N}$ & $\mathrm{N}$ & $\mathrm{N}$ \\
\hline $\begin{array}{l}\text { Journal of the National } \\
\text { Cancer Institute }\end{array}$ & Mauri et $a f^{42} ;$ Kyrgiou et $a{ }^{48}$ & 14.697 & Y, online & 6000 & 8 table or figures & 8 tables or figures \\
\hline Lancet & Cipriani et $a{ }^{35}$ & 33.633 & Y, online & 4500 & $\begin{array}{l}\text { "Should include } \\
\text { about } 5 \text { illustrations" }\end{array}$ & $\begin{array}{l}\text { "Should include } \\
\text { about } 5 \text { illustrations" }\end{array}$ \\
\hline Lancet Infectious Disease & Manzoli et $a^{\beta 9}$ & 16.144 & Y, online & $3000-5000$ & $\begin{array}{l}\text { "Should include } \\
\text { about } 5 \text { illustrations" }\end{array}$ & $\begin{array}{l}\text { "Should include } \\
\text { about } 5 \text { illustrations" }\end{array}$ \\
\hline Lancet Oncology & Golfinopoulos et $\left.a\right|^{44} ;$ Bangalore $^{15}$ & 17.764 & Y, online & $3000-5000$ & $\begin{array}{l}\text { "Should include } \\
\text { about } 5-6 \\
\text { illustrations" }\end{array}$ & $\begin{array}{l}\text { "Should include } \\
\text { about } 5-6 \\
\text { illustrations" }\end{array}$ \\
\hline
\end{tabular}




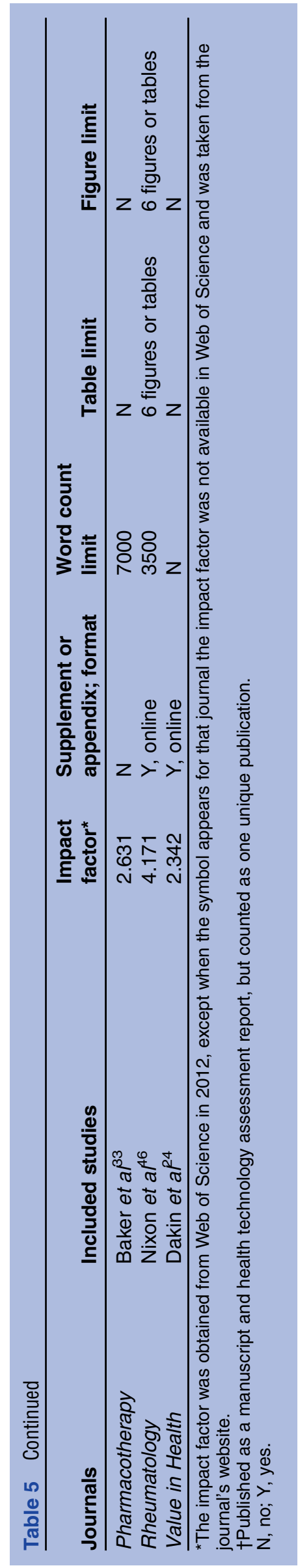

aggregated study-level data. Despite these differences, however, our findings are consistent with prior research and with the opinion of experts regarding the challenges and concerns around implementing and reporting these more complex statistical methods. ${ }^{10} \quad 12 \quad 52$ Perhaps clearer guidance as to how to conduct and report these types of meta-analyses will lead to a more optimal and consistent approach.

While we only characterised the methods and reporting of closed-loop Bayesian MTC in this report, our search strategy was designed to capture MTCs regardless of methodological approach (including frequentist MTC). Of note, only a handful $(n=9)$ of frequentist MTCs were identified in our search, three of which specifically reference using the methods for MTC proposed by Lumley and colleagues, while the others more generically referenced mixed-model approaches. ${ }^{49} 53-60$ This suggests that meta-analysts at present seem to favour a Bayesian approach to MTC, since investigators could have chosen to use either a Bayesian or frequentist method for any of the MTC identified in our search (given all analysed networks with at least one closed loop). Given the relative paucity of frequentist models, we do not describe the characteristics of their methods and reporting in this paper but they can be found elsewhere. ${ }^{11}$

An important limitation of our review is that we cannot say with certainty that a lack of reporting means a given method or analysis was not undertaken (ie, the testing for convergence or inconsistency need not be described in a paper for it to have been performed by the investigators) or that the reporting of a piece of data or statistical code was not considered. However, we evaluated word, table and figure limits imposed by journals in which these MTCs were published and our findings do not suggest journal space should be an obstacle to complete reporting. Another limitation is the definition used to describe a methodologist. While this definition has been used by previous researchers in a similar topic area, ${ }^{13}$ to our knowledge it has not been validated and therefore may not accurately depict the true involvement of an individual who considered themselves a methodologist.

With the growing publication of Bayesian MTCs in the peer-reviewed literature and the recognised challenges of such methods, its appropriate use and interpretation becomes imperative. Efforts in clarifying the appropriate use and reporting of Bayesian MTC should be of priority.

Contributors DMS, JCC, CIC, WLB, OJP and CMW were responsible for study design. DMS, WLB and OJP were responsible for data collection. DMS, CIC and JCC were responsible for data analysis and interpretation. All authors contributed in drafting the manuscript, revising the manuscript and approved the final manuscript. $\mathrm{CIC}$ is responsible for the overall content as the corresponding author.

Funding This work was supported by the Agency for Healthcare Research and Quality contract number HHSA 290200710067 I.

Competing interests None. 
Provenance and peer review Not commissioned; externally peer reviewed.

Data sharing statement Individual study data that has been extracted can be found by accessing the full report on the AHRQ EHC website.

Open Access This is an Open Access article distributed in accordance with the Creative Commons Attribution Non Commercial (CC BY-NC 3.0) license, which permits others to distribute, remix, adapt, build upon this work noncommercially, and license their derivative works on different terms, provided the original work is properly cited and the use is non-commercial. See: http:// creativecommons.org/licenses/by-nc/3.0/

\section{REFERENCES}

1. Bucher HC, Guyatt GH, Griffith LE, et al. The results of direct and indirect treatment comparisons in meta-analysis of randomized controlled trials. J Clin Epidemiol 1997;50:683-91.

2. Lumley T. Network meta-analysis for indirect treatment comparisons. Stats Med 2002;21:2313-24.

3. Jansen JP, Fleurence R, Devine B, et al. Interpreting indirect treatment comparisons and network meta-analysis for health-care decision making: report of the ISPOR Task Force on Indirect Treatment Comparisons Good Research Practices: part 1. Value Health 2011:14:417-28.

4. Hoaglin DC, Hawkins N, Jansen JP, et al. Conducting indirect-treatment-comparison and network-meta-analysis studies: report of the ISPOR Task Force on Indirect Treatment Comparisons Good Research Practices: part 2. Value Health 2011;14:429-37.

5. Sutton A, Ades AE, Cooper N, et al. Use of indirect and mixed treatment comparisons for technology assessments. Pharmacoeconomics 2008;26:753-67.

6. Lu G, Ades AE. Combination of direct and indirect evidence in mixed treatment comparisons. Stat Med 2004;23:3105-24.

7. Caldwell DM, Ades AE, Higgins PT. Simultaneous comparison of multiple treatments: combining direct and indirect evidence. $B M J$ 2005;331:897-900.

8. Health Information and Quality Authority. Guidelines for evaluating the clinical effectiveness of health technologies in Ireland. Dublin: Health Information and Quality Authority, 2011. http://www.hiqa.ie (accessed 28 Dec 2011).

9. Donegan S, Williamson P, Gamble C, et al. Indirect comparisons: a review of reporting and methodological quality. PLOS ONE 2010;5: e11054.

10. Song F, Loke YK, Walsh T, et al. Methodological problems in the use of indirect comparisons for evaluating healthcare interventions: survey of published systematic reviews. BMJ 2009;338:b1147.

11. Coleman Cl, Phung OJ, Cappelleri JC, et al. Use of mixed treatment comparisons in systematic reviews. Methods Research Report. (Prepared by the University of Connecticut/Hartford Hospital Evidence-based Practice Center under Contract No. 2902007 10067I.) AHRQ Publication No. 12-EHC119-EF. Rockville, MD Agency for Healthcare Research and Quality. August 2012.

12. Salanti G. Indirect and mixed-treatment comparison, network, or multiple-treatments meta-analysis: many names, many benefits, many concerns for the next generation evidence synthesis tool. Res Synth Method 2012;3:80-97.

13. Sung L, Hayden J, Greenberg ML, et al. Seven items were identified for inclusion when reporting a Bayesian analysis of a clinical study. $J$ Clin Epidemiol 2005:58:261-8.

14. Canadian Agency for Drugs and technologies in Health. Guidelines for the economic evaluation of health technologies: Canada. 3rd edn. Ottawa: Canadian Agency for Drugs and Technologies in Health, 2006. http://www.cadth.ca (accessed 28 Dec 2011).

15. Bangalore S, Kumar S, Kjeldsen E, et al. Antihypertensive drugs and risk of cancer: network meta-analyses and trial sequential analysis of 324168 participants from randomized trials. Lancet Oncol 2011:12:65-82.

16. Gross JL, Kramer CK, Leitao CB, et al. Effect of antihyperglycemics agents added to metformin and a sulfonylurea on glycemic control and weight gain in type 2 diabetes: a network meta-analysis. Ann Intern Med 2011;154:672-9.

17. Hartling L, Fernandes RM, Bialy L, et al. Steroids and bronchodilators for acute bronchiolitis in the first two years of life: systematic review and meta-analysis. BMJ 2011;342:1714.

18. Maund E, McDaid C, Rice S, et al. Paracetamol and selective and non-selective non-steroidal anti-inflammatory drugs for the reduction in morphine-related side-effects after major surgery: a systematic review. Br J Anaesth 2011;106:292-7.

19. McDaid C, Maund E, Rice S, et al. Paracetamol and selective and non-selective non-steroidal anti-inflammatory drugs (NSAIDs) for the reduction of morphine-related side effects after major surgery: a systematic review. Health Technol Assess 2010;14:1-153.

20. Sciarretta S, Palano F, Tocci G, et al. Antihypertensive treatment and development of heart failure in hypertension: a Bayesian network meta-analysis of studies in patients with hypertension and high cardiovascular risk. Arch Intern Med 2011;171:384-94.

21. Trelle S, Reichenback S, Wandel S, et al. Cardiovascular safety of non-steroidal anti-inflammatory drugs: network meta-analysis. BMJ 2011;342:c7086.

22. van de Kerkhof $P$, de Peuter R, Ryttov J, et al. Mixed treatment comparison of a two-compound formulation (TCF) product containing calcipotriol and betamethasone dipropionate with other topical treatments in psoriasis vulgaris. Curr Med Res Opin 2011;27:225-38.

23. Van den Bruel A, Gailly J, Devriese S, et al. The protective effect of ophthalmic viscoelastic devices on endothelial cell loss during cataract surgery: a meta-analysis using mixed treatment comparisons. Br J Ophthalmol 2011;95:5-10.

24. Dakin H, Fidler C, Harper C. Mixed treatment comparison meta-analysis evaluating the relative efficacy of nucleos(t)ides for treatment of nucleos $(\mathrm{t})$ ide-naive patients with chronic hepatitis $\mathrm{B}$. Value Health 2010;13:934-45.

25. Orme M, Collins S, Dakin $\mathrm{H}$, et al. Mixed treatment comparison and meta-regression of the efficacy and safety of prostaglandin analogues and comparators for primary open-angle glaucoma and ocular hypertension. Curr Med Res Opin 2010;26:511-28.

26. Phung OJ, Scholle JM, Talwar M, et al. Effect of noninsulin antidiabetic drugs added to metformin therapy on glycemic control, weight gain, and hypoglycemia in type 2 diabetes. JAMA 2010;303:1410-18.

27. Uthman OA, Abdulmalik J. Comparative efficacy and acceptability of pharmacotherapeutic agents for anxiety disorders in children and adolescents: a mixed treatment comparison meta-analysis. Curr Med Res Opin 2010;26:53-9.

28. Vissers D, Stam W, Nolte T, et al. Efficacy of intranasal fentanyl spray versus other opioids for breakthrough pain in cancer. Curr Med Res Opin 2010;26:1037-45.

29. Walsh T, Worthington HV, Glenn A, et al. Fluoride toothpastes of different concentrations for preventing dental caries in children and adolescents. Cochrane Database Syst Rev 2011;(1):CD007868.

30. Wandel S, Juni P, Tendal B, et al. Effects of glucosamine chondroitin, or placebo in patients with osteoarthritis of hip or knee: network meta-analysis. BMJ 2010;341:4675.

31. Wang $\mathrm{H}$, Huang $\mathrm{T}$, Jing $\mathrm{J}$, et al. Effectiveness of different central venous catheters for catheter-related infections: a network meta-analysis. J Hosp Infect 2010;76:1-11.

32. Woo G, Tomlinson G, Nishikawa $Y$, et al. Tenofovir and entecavir are the most effective antiviral agents for chronic hepatitis $B:$ a systematic review and Bayesian meta-analyses. Gastroenterology 2010;139:1218-29.

33. Baker WL, Baker EL, Coleman Cl. Pharmacologic treatments for chronic obstructive pulmonary disease: a mixed-treatment comparison meta-analysis. Pharmacotherapy 2009;29:891-905.

34. Bansback N, Sizto S, Sun H, et al. Efficacy of systemic treatments for moderate to severe plaque psoriasis: systematic review and meta-analysis. Dermatology 2009;219:209-18.

35. Cipriani A, Furukawa TA, Salanti G, et al. Comparative efficacy and acceptability of 12 new-generation antidepressants: a multiple-treatments meta-analysis. Lancet 2009;373:746-58.

36. Edwards SJ, Lind T, Lundell L, et al. Systematic review: standardand double-dose proton pump inhibitors for the healing of severe erosive oesophagitis - a mixed treatment comparison of randomized controlled trials. Aliment Pharmacol Ther 2009:30:547-56.

37. Edwards SJ, Smith CJ. Tolerability of atypical antipsychotics in the treatment of adults with schizophrenia or bipolar disorder: a mixed treatment comparison of randomized controlled trials. Clin Ther 2009;31(Pt 1):1345-59.

38. Golfinopoulos V, Pentheroudakis G, Salanti G, et al. Comparative survival with diverse chemotherapy regimens for cancer of unknown primary site: multiple-treatments meta-analysis. Cancer Treat Rev 2009:35:570-3.

39. Manzoli L, Georgia S, De Vito C, et al. Immunogenicity and adverse events of avian influenza A H5N1 vaccine in healthy adults: multiple-treatments meta-analysis. Lancet Infect Dis 2009;9:481-92.

40. Meader N. A comparison of methadone, buprenorphine and alpha2 adrenergic agonists for opiod detoxification: a mixed treatment comparison meta-analysis. Drug Alcohol Depen 2010;108:110-14.

41. Coleman $\mathrm{Cl}$, Baker WL, Kluger J, et al. Antihypertensive medication and their impact on cancer incidence: a mixed treatment comparison meta-analysis of randomized controlled trials. J Hypertens 2008;26:622-9. 
42. Mauri D, Polyzos NP, Salanti G, et al. Multiple-treatments meta-analysis of chemotherapy and targeted therapies in advanced breast cancer. J Natl Cancer Inst 2008;100:1780-91.

43. Stettler C, Allemann S, Wandel S, et al. Drug eluting and bare metal stents in people with and without diabetes: collaborative network meta-analysis. BMJ 2008;337:a1331.

44. Golfinopoulos V, Salanti G, Pavlidis N, et al. Survival and disease-progression benefits with treatment regimens for advanced colorectal cancer: a meta-analysis. Lancet Oncol 2007;8:898-911.

45. Lam SK, Owen A. Combined resynchronisation and implantable defibrillator therapy in left ventricular dysfunction: Bayesian network meta-analysis of randomised controlled trials. BMJ 2007;335:925.

46. Nixon R, Bansback N, Brennan A. The efficacy of inhibiting tumour necrosis factor alpha and interleukin 1 in patients with rheumatoid arthritis: a meta-analysis and adjusted indirect comparisons. Rheumatology 2007;46:1140-7.

47. Cooper NJ, Sutton AJ, Lu G, et al. Mixed comparison of stroke prevention treatments in individuals with nonrheumatic atrial fibrillation. Arch Intern Med 2006;166:1269-75.

48. Kyrgiou M, Salanti G, Pavlidis N, et al. Survival benefits with diverse chemotherapy regimens for ovarian cancer: meta-analysis of multiple treatments. J Natl Cancer Inst 2006;98:1655-63.

49. Baldwin $D$, Woods $R$, Lawson $R$, et al. Efficacy of drug treatments for generalized anxiety disorder: systematic review and meta-analysis. BMJ 2011;342:1199.

50. Patsopoulos NA, Analatos AA, loannidis JPA. Relative citation impact of various study designs in the health sciences. JAMA 2005;293:2362-6.

51. Davey J, Turner RM, Clarke MJ, et al. Characteristics of meta-analyses and their component studies in the Cochrane
Database of Systematic Reviews: a cross-sectional, descriptive analysis. BMC Med Res Methodol 2011;11:160.

52. Li T, Puhan MA, Vedula SS, et al. Ad Hoc Network Meta-analysis Methods Meeting Working Group. Network meta-analysis-highly attractive but more methodological research is needed. BMC Med 2011;9:79.

53. Freemantle N, Lafuente-Lafuente C, Mitchell S, et al. Mixed treatment comparison of dronedarone, amiodarone, sotalol, flecainide, and propafenone, for the management of atrial fibrillation. Europace 2011;13:329-45.

54. Anothaisintawee T, Attia J, Nickel JC, et al. Management of chronic prostatitis/chronic pelvic pain syndrome: a systematic review and network meta-analysis. JAMA 2011;305:78-86.

55. Hansen RA, Gaynes BN, Gartlehner G, et al. Efficacy and tolerability of second-generation antidepressants in social anxiety disorder. Int Clin Psychopharmacol 2008;23:170-9.

56. Jalota L, Kalira V, George E, et al. Prevention of pain on injection of propofol: systematic review and meta-analysis. BMJ 2011;342:1110.

57. Trikalinos TA, Alsheikh-Ali AA, Tatsioni A, et al. Percutaneous coronary interventions for non-acute coronary artery disease: a quantitative 20 -year synopsis and a network meta-analysis. Lancet 2009;373:911-18.

58. Elliott WJ, Meyer PM. Incident diabetes in clinical trials of antihypertensive drugs: a network meta-analysis. Lancet 2007;369:201-7.

59. Singh JA, Wells GA, Christensen R, et al. Adverse effects of biologics: a network meta-analysis and Cochrane overview (review). Cochrane Database Syst Rev 2011;2:CD008794.

60. Roskell NS, Lip GYH, Noack H, et al. Treatments for stroke prevention in atrial fibrillation: a network meta-analysis and indirect comparison versus dabigatran etexilate. Thromb Haemost 2010;104:1106-15. 